\title{
Effects of Molecular Weight and Its Distribution on Fractural Behavior of Polystyrene*
}

\author{
Shigeharu Onogi, Takayoshi Matsumoto, and Eiichi KameI \\ Department of Polymer Chemistry, Kyoto University, Kyoto, Japan.
}

(Received November 9, 1971)

\begin{abstract}
The effects of molecular weight and its distribution on fractural properties of polystyrene were studied at several elevated temperatures and various rates of strain. Logarithmic plots of ultimate strength $\sigma_{\mathrm{f}}$ against ultimate rate of strain $\dot{\gamma}_{\mathrm{f}}$, as well as of ultimate strain $\gamma_{\mathrm{f}}$ against $\dot{\gamma}_{\mathrm{f}}$ at various temperatures, can be superposed by horizontal shifting into respective smooth master curves, giving the same shift factors. The shift factors are of the WLF type.

Fractural behavior can be distinguished into four regions: brittle to ductile, ductile, ductile to flow, and flow regions. The effect of molecular weight is notable especially in the third and fourth regions. $\sigma_{\mathrm{f}}$ and $\gamma_{\mathrm{f}}$ plotted against $\dot{\gamma}_{\mathrm{f}}$ become lower and lower as molecular weight decreases. When a low molecular weight component is included, $\sigma_{\mathrm{f}}$ and $\gamma_{f}$ plotted against $\dot{\gamma}_{f}$ shift to the short. time-scale (high-rate strain) side.

KEY WORDS Fracture / Polystyrene / Molecular Weight Distribution / Molecular Weight / Time-Temperature Superposition /
\end{abstract}

The fractural properties of high polymers, especially of vulcanized rubbers and glassy polymers, have been studied by many authors ${ }^{1-3}$ and some results obtained in the field of linear viscoelasticity have been applied to these properties on the basis of the thought that the fractural properties are governed by the some relaxation processes. $^{4-8}$

On the other hand, according to Coleman ${ }^{9-11}$ and Kawabata, et al., ${ }^{12}$ the fractural properties of fibers and vulcanized rubbers are essentially dominated by stochastic or statistic processes. Recent developments in studies of linear and nonlinear viscoelastic properties of uncrosslinked amorphous polymers are stimulating studies on fractural properties of these polymers. However, there have been only a few studies on effects of molecular weight and its distribution on the fractural properties of these materials.

For several years, the authors have devoted themselves to research on the effects of molecular weight and its distribution on the rheological properties of several kinds of polymers such as polystyrene ${ }^{13,14}$ and poly(methyl methacrylate).$^{15,16}$

* Presented at the International Conference on Mechanical Behavior of Materials, Kyoto, August 16-20, 1971.
As a part of these investigations, the effects of molecular weight and its distribution on the fractural properties of polystyrene at elevated temperatures were studied and are reported in this paper.

\section{EXPERIMENTAL}

\section{Materials}

The materials employed in this study were monodisperse, fractionated, unfractionated, and blended polystyrenes similar to those used in previous studies. ${ }^{13,14}$ Molecular weight distributions of all the samples were measured by means of the gel-permeation chromatograph, Model 200, manufactured by Waters Associates Inc.

The weight- and number-average molecular weights and their ratios for the samples employed are tabulated in Table I. In this table, the four L-series samples are narrow-distribution polystyrene obtained by anionic polymerization, while PS9w and PS10w are unfractionated whole polymers prepared by bulk polymerization, and PS10f is a fraction of the last. The weightaverage molecular weights $M_{w}$ of the narrowdistribution polystyrenes L3, L51, and L52 were determined from the intrinsic viscosity [ $\eta]$ of solutions in cyclohexane at $34.5^{\circ} \mathrm{C}$, using the 
Table I. The weight- and number-average molecular weights and the ratios of these values for the polymers used.

\begin{tabular}{lccc}
\hline \multirow{2}{*}{ Sample } & \multicolumn{2}{c}{ Mol wt $\times 10^{-4}$} & $M_{w} / M_{n}$ \\
\cline { 2 - 3 } & $M_{w}$ & $M_{n}$ & \\
\hline L3 & 2.45 & 2.26 & 1.08 \\
L51 & 38.8 & 34.4 & 1.13 \\
L52 & 13.1 & 14.1 & 0.93 \\
L54 & 60.0 & 50.7 & 1.18 \\
PS9w & 37.4 & 22.7 & 1.65 \\
PS10w & 97.4 & 44.1 & 2.20 \\
PS10f & 150 & 81.3 & 1.85 \\
\hline
\end{tabular}

following equation as proposed by Altares, et al., ${ }^{17}$

$$
[\eta]=8.5 \times 10^{-4} M_{w}{ }^{0.5}
$$

$M_{w}$ values for L54, PS9w, PSIOw, and PS10f, on the other hand, were determined by using the following equation, proposed by Ogami, et al., ${ }^{18}$ for toluene solutions at $30^{\circ} \mathrm{C}$.

$$
[\eta]=1.20 \times 10^{-4} M_{w}^{0.71}
$$

The number-average molecular weight $M_{n}$ was determined by the osmotic pressure method using the high-speed membrane osmometer Model 502 of Mecrolab Inc.

The blending of two samples having different molecular weights was carried out by dissolving suitable mixtures of the components in benzene with shaking to obtain uniform solutions of 10 to $20 \mathrm{wt} \%$. The solvent was then removed by freeze-drying. The blends thus obtained were then thoroughly dried in a vacuum oven at $65^{\circ} \mathrm{C}$.

To obtain sample films, polymers were meltpressed at $200^{\circ} \mathrm{C}$ for about $5 \mathrm{~min}$ in a laboratory press and cooled to room temperature. The thickness of the films was about $0.5 \mathrm{~mm}$.

Rectangular specimens $3 \mathrm{~cm}$ in length and $1 \mathrm{~cm}$ in width were cut from the films and were subjected to stress-strain tests.

\section{Measurements}

Stress-strain tests were carried out by means of an Instron-type tensile tester, Tensilon UTM $\mathrm{III}$, over wide ranges of temperature $\left(115-180^{\circ} \mathrm{C}\right)$ and rate of elongation $(0.028-0.56 \mathrm{~cm} / \mathrm{sec})$. The ultimate strength $\sigma_{f}$ and ultimate elongation $\gamma_{\mathrm{f}}$ were obtained from the stress-strain curves.

The strain $\gamma$ and the strain rate $\dot{\gamma}$ were defined as follows

$$
\begin{aligned}
& \gamma=\ln \left(L / L_{0}\right) \\
& \dot{\gamma}=v / L
\end{aligned}
$$

where $L_{0}$ and $L$ are respectively the initial length and the length at an arbitrary time $t$, and $v$ is the tensile speed. The strain was determined from measurements of the separation of two fiducial lines drawn beforehand on the specimen. The tensile stress $\sigma$ was corrected for the change in cross-sectional area; that is, it is the true stress rather than the engineering stress.

\section{RESULTS :AND DISCUSSION}

\section{Temperature Dependence of Fractural Properties}

As an example of stress-strain curves obtained for the polystyrene samples the result for PS10f is shown in Figure 1. The curves at higher temperatures are convex upward, while those at lower temperatures are convex downward at larger strains. The maximum point of each curve, noted by a closed circle in the figure, was designated as the breaking point; because after this point the material in the middle of test specimen actually contracts somewhat, despite the fact that

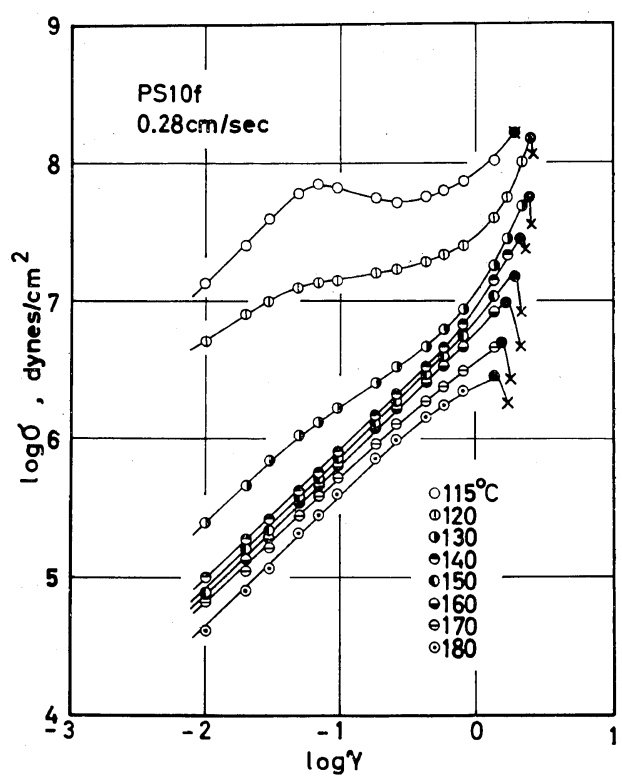

Figure 1. Logarithmic stress - strain curves at various temperatures for PS10f at an elongation rate of $0.28 \mathrm{~cm} / \mathrm{sec}$. 


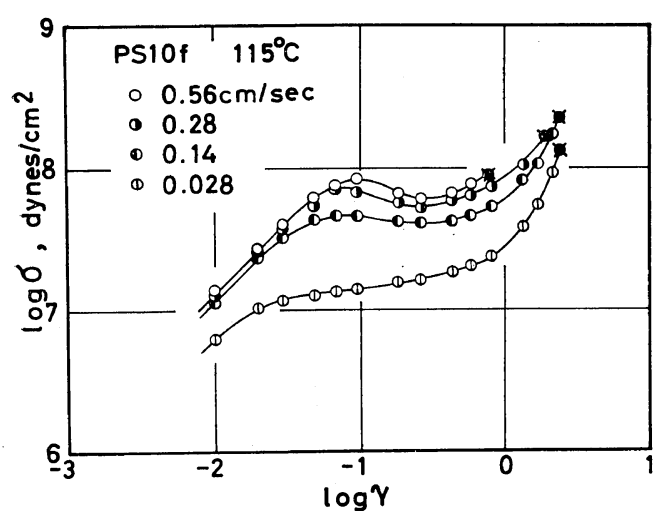

Figure 2. Logarithmic plots of stress-strain curves at various rates of elongation for PS10f at $115^{\circ} \mathrm{C}$.

the test specimen is still stretched at the clamped ends, and the stress falls abruptly. The test specimens actually broke at the points noted by cross marks in the figure.

In Figure 2, the stress-strain curves obtained for PS10f at $115^{\circ} \mathrm{C}$ at various rates of elongation ranging from 0.028 to $0.56 \mathrm{~cm} / \mathrm{sec}$ are shown. The dependence of the stress-strain curves on the rate of elongation appears very similar to that on temperature; high and low rates of elongation correspond respectively to low and high temperatures. This fact indicates that an equivalence holds between time and temperature as in the case of linear viscoelasticity of amorphous polymers.

The stress-strain curves shown in Figures 1 and 2 can be distinguished into the following four types.

(1) Type 1 shows a yield point, and the specimen breaks without showing a remarkable increase in stress in the final stage. This type is observed at low temperatures or high rates of elongation.

(2) Type 2 shows a yield point, and the specimen breaks after a remarkable increase in stress.

(3) In Type 3, stress is approximately proportional to strain till the breaking point.

(4) In Type 4, stress is proportional to strain at smaller strains, but increases rapidly at higher strains.

Corresponding to these four types of stressstrain curves, fractural properties over a wide

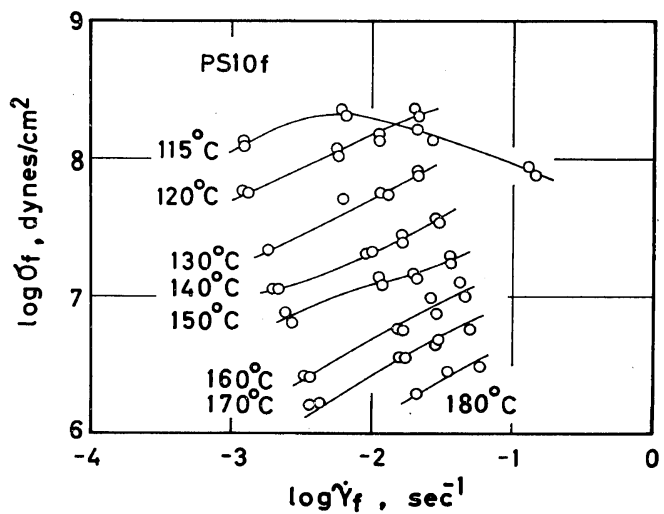

Figure 3. Logarithmic plots of ultimate strength $\sigma_{f}$ against ultimate rate of strain $\dot{\gamma}_{f}$ at various temperatures for PS10f.

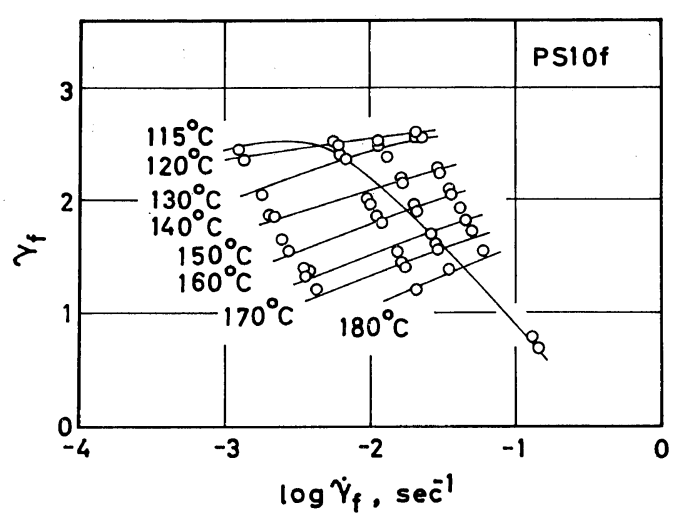

Figure 4. Plots of ultimate strain $\gamma_{\mathrm{f}}$ against $\log \dot{\gamma}_{\mathrm{f}}$ at various temperatures for PS10f.

range of time-scale can be divided into four regions as will be discussed later.

Logarithmic plots of the ultimate strength $\sigma_{\mathrm{f}}$ against the ultimate rate of strain $\dot{\gamma}_{f}$ as well as of the ultimate strain $\gamma_{f}$ against $\dot{\gamma}_{f}$ for PS10f at various temperatures are shown in Figures 3 and 4 , respectively. The curves at different temperatures can be superposed by horizontal shifting into respective master curves. Figures 5 and 6 show the master curves of $\sigma_{\mathrm{f}}$ and $\gamma_{\mathrm{f}}$ for PS10f and two other samples, PS10w and PS9w. The abscissa of the figures is the reduced rate of strain $\dot{\gamma}_{\mathrm{T}} s_{\mathrm{T}}$, where $s_{\mathrm{T}}$ is the shift factor. As is evident from these figures, the superposition is satisfactory enough to give smooth master curves. The shift factor $s_{\mathrm{T}}$ determined in the course of 


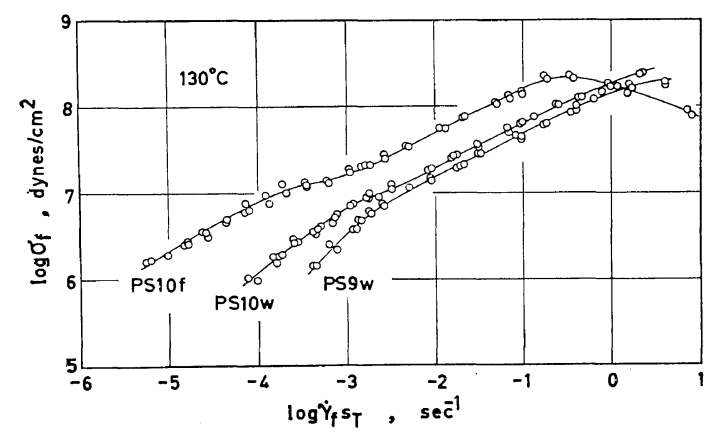

Figure 5. Master curves of $\sigma_{f}$ for PS10f, PS10w, and PS9w at $130^{\circ} \mathrm{C}$.

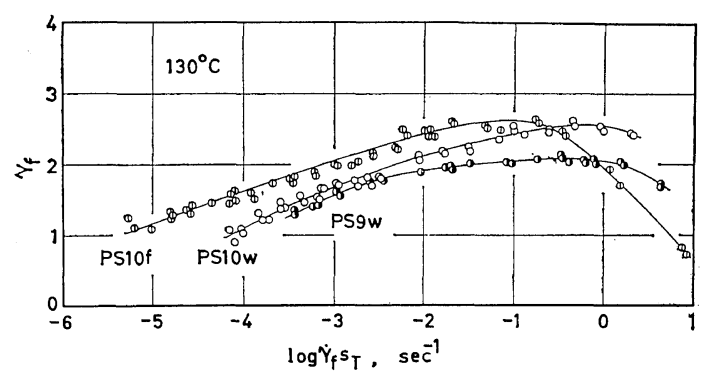

Figure 6. Master curves of $\gamma_{f}$ for PS10f, PS10w, and PS9w at $130^{\circ} \mathrm{C}$.

the superposition of the $\sigma_{\mathrm{f}}$ and $\gamma_{\mathrm{f}}$ curves showed the same values at the same temperatures in both cases, and is of the WLF type. In Figure 7, the shift factor $s_{\mathrm{T}}$ as a function of temperature is compared with the shift factor $a_{\mathrm{T}}$ determined from the dynamic viscoelastic properties of the same materials. $s_{\mathrm{T}}$ is somewhat smaller over the entire temperature range covered, but it is not clear whether this difference is due to an essential difference between linear viscoelasticity and frac-

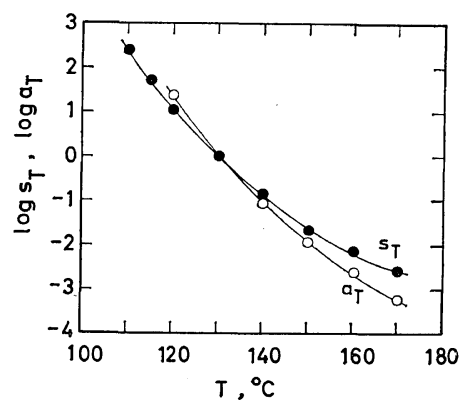

Figure 7. Temperature dependences of the shift factors $s_{\mathrm{T}}$ and $\boldsymbol{a}_{\mathrm{T}}$.

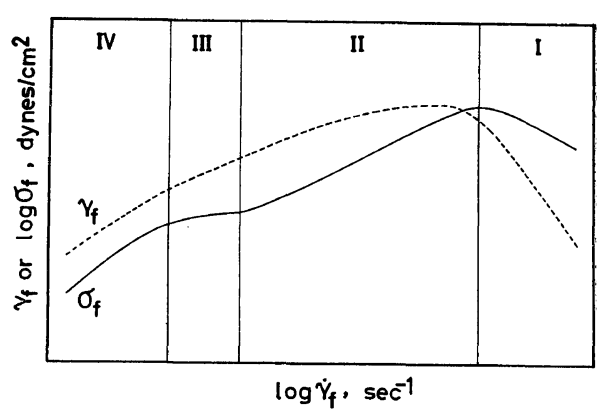

Figure 8. Schematic master curves of $\sigma_{f}$ and $\gamma_{f}$ : solid line, $\log \sigma_{\mathrm{f}} v s . \log \dot{\gamma}_{\mathrm{f}}$; dotted line, $\gamma_{\mathrm{f}} v s . \log \dot{\gamma}_{\mathrm{f}}$.

tural behavior or not.

The master curves of ultimate strength for the samples can generally be divided into four regions, I to IV, as is schematically shown in Figure 8. Region $I$ is the brittle to ductile transition region, where the material behaves in a rather glass-like manner. Region II is the ductile region where the material behaves as a typical viscoelastic material. In Region IV, the material behaves as a viscous liquid. Region III is just intermediate between Regions II and IV, and appears only for samples having weight-average molecular weights higher than $1 \times 10^{6}$.

The master curves of ultimate strain show maxima similarly to the master curves of ultimate strength, but they can not clearly be distinguished into the same four regions. These four regions in the master curves correspond to the characteristic four types of stress-strain curves at various temperatures or rates of elongation mentioned above.

For vulcanized rubbers, master curves of the ultimate strength plotted against the reduced ultimate rate of strain are sigmoidal in shape, and Region III mentioned above continues to lower rates of strain while Region IV does not appear. These differences in behavior between vulcanized rubbers and uncrosslinked polymers are obviously dependent on whether three dimensional networks are formed by chemical crosslinking or by entanglements between molecular chains.

Dependences of Fractural Properties on Molecular Weight and Its Distribution

The master curves of the ultimate strength and ultimate strain for the narrow-distribution polystyrenes are shown respectively in Figures 9 and 


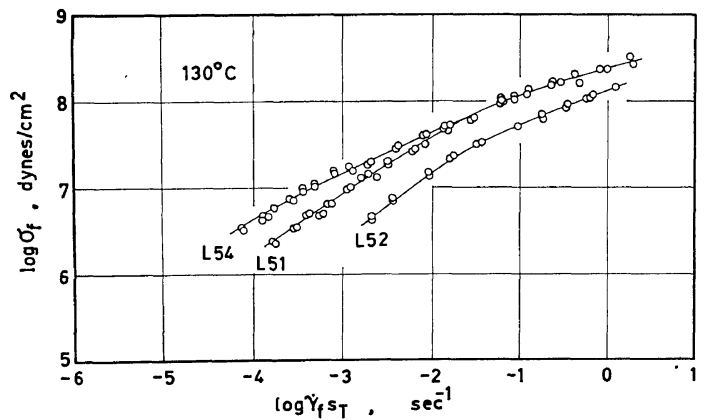

Figure 9. Master curves of $\sigma_{\mathrm{f}}$ for narrow-distribution polystyrenes L54, L51, and L52 at $130^{\circ} \mathrm{C}$.

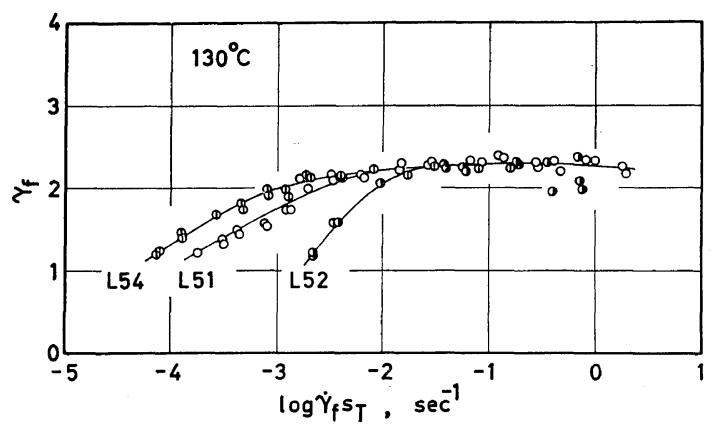

Figure 10. Master curves of $\gamma_{f}$ for narrow-distribution polystyrenes L54, L51, and L52 at $130^{\circ} \mathrm{C}$.

10. In general, the effect of molecular weight on fractural behavior can be observed over the entire range of rate of strain or time-scale covered by this study, but most remarkably in Regions III and IV, and less remarkably in Regions I and II or at shorter time-scales.

In Figure 11, the gel-permeation chromatograms for PS10f and PS10w are compared. As is evident from this figure, PS10f does not contain the low molecular weight components included in PS10w. As seen in Figures 5 and 6, the ultimate strength and ultimate strain for PS10f are much higher than those for PS10w at lower rates of strain or longer time-scale. The difference is attributable to the difference in molecular weight distributions of these two polymers. In other words, low molecular weight components lower the ultimate strength and ultimate strain at longer time-scales.

Similar effect of molecular weight distribution can also be seen in the master curves of $\sigma_{f}$

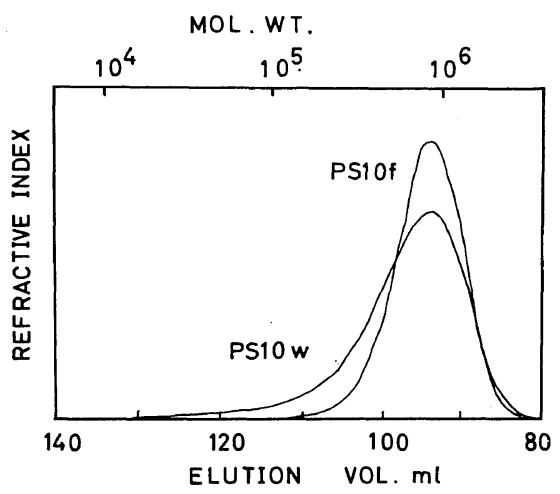

Figure 11. Gel-permeation chromatograms for PS10f and PS10w. The scale of refractive index is arbitrary.

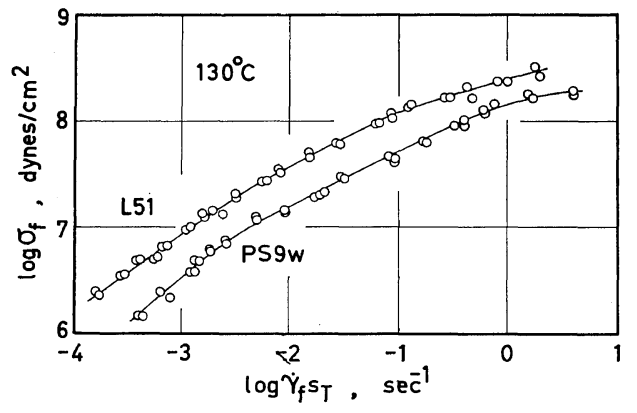

Figure 12. Master curves of $\sigma_{\mathrm{f}}$ for the narrowand broad-distribution prlystyrenes L51 and PS9w at $130^{\circ} \mathrm{C}$.

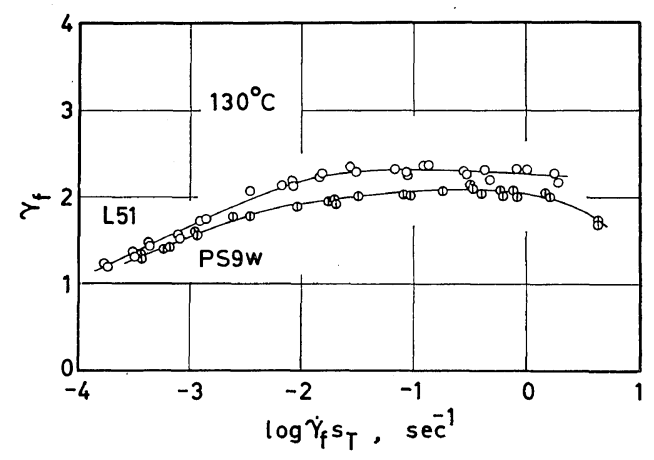

Figure 13. Master curves of $\gamma_{f}$ for the narrowand broad-distribution polystyrenes L51 and PS9w at $130^{\circ} \mathrm{C}$.

and $\gamma_{f}$ shown in Figures 12 and 13 for the narrowdistribution polystyrene L51 and the broad distribution PS9w. The weight-average molecular 


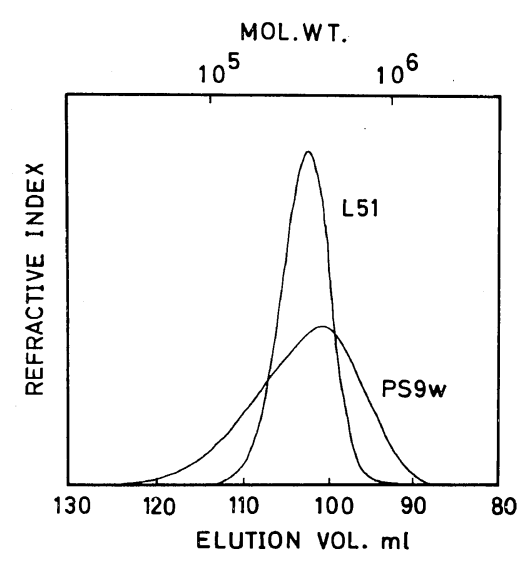

Figure 14. Gel-permeation chromatograms for L51 and PS9w. The scale of refractive index is arbitrary.

weights of these two polymers are almost the same but the number-average molecular weight of L51 is higher than that of PS9w. The gelpermeation chromatograms for these two polymers are compared in Figure 14. As is evident from this figure, PS9w has a distribution broader than L51, and it contains not only low molecular weight components but also high molecular weight components. Regardless of the existence of high molecular weight components, however, PS9w shows much lower $\sigma_{f}$ and $\gamma_{f}$ over the entire range of rate of strain, indicating that the effect of small molecules on fractural properties is very strong.

In order to make this effect of clearer, fractural properties of blends of two polymers of different molecular weights were measured. The high-molecular-weight component was L54, having the weight-average molecular weight of $60.0 \times 10^{4}$; while the low molecular weight component was $\mathrm{L3}$, of which the weight-average molecular weight is $2.45 \times 10^{4}$. The former is higher than the critical molecular weight $M_{\mathrm{C}}$ for polystyrene, while the latter is lower than $M_{\mathrm{C}}$. The master curves of $\sigma_{\mathrm{f}}$ and $\gamma_{\mathrm{f}}$ for L54 and its blends, B18, B17, and B16, with L3 are shown in Figures 15 and 16. The contents of the high molecular weight component, L54, of $\mathrm{B} 18, \mathrm{~B} 17$, and B16 were respectively 80, 70, and $60 \%$. As the content of the high-molecularweight component decreases, $\sigma_{\mathrm{f}}$ at a given rate of strain decreases remarkably, and the master

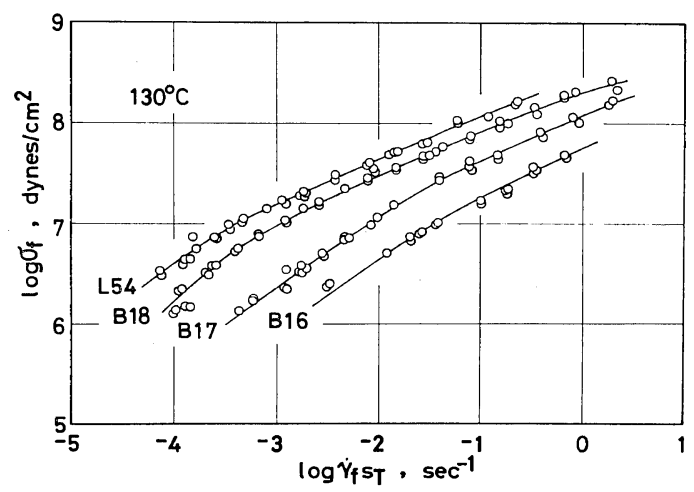

Figure 15. Master curves of $\sigma_{\mathrm{f}}$ for three blended polystyrenes, B18, B17, and B16, and L54 at $130^{\circ} \mathrm{C}$.

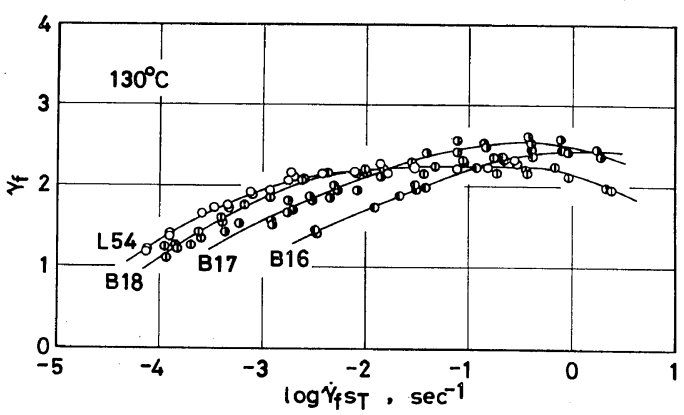

Figure 16. Master curves of $\gamma_{\mathrm{f}}$ for three blended polystyrenes, B18, B17, and B16, and $\mathrm{L} 54$ at $130^{\circ} \mathrm{C}$.

curves of $\gamma_{\mathrm{f}}$ plotted against the ultimate rate of strain shift to the high rate of strain or long time-scale side.

Acknowledgement. This study was supported by a grant for scientific research (KagakuKenkyu-hi) from the Ministry of Education, Japan.

\section{REFERENCES}

1. B. R. Rosen, Ed., "Fracture Processes in Polymeric Solids", Interscience Publishers, Inc., New York, N.Y., 1964.

2. J. C. Halpin and F. Bueche, J. Appl. Phys., 35, 3133 (1964).

3. T. L. Smith and R. A. Dickie, J. Polym. Sci., Part A-2, 7, 635 (1969).

4. T. L. Smith, ibid., 32, 99 (1958).

5. T. L. Smith, J. Appl. Phys., 35, 27 (1964).

6. F. Bueche, ibid., 26, 1133 (1955).

7. F. Bueche, ibid., 28, 784 (1957). 
8. F. Bueche, ibid., 29, 1231 (1958).

9. B. D. Coleman, ibid., 27, 862 (1956).

10. B. D. Coleman, ibid., 28, 1058 (1957).

11. B. D. Coleman and D. W. Marquardt, ibid., 28, 1065 (1957).

12. S. Kawabata, S. Tatsuta, and H. Kawai, Proceedings of 5th International Congress on Rheology, Vol. 3, 112 (1970).

13. S. Onogi, T. Masuda, and K. Kitagawa, Macromolecules, 3, 109 (1970).

14. T. Masuda, K. Kitagawa, T. Inoue, and $\mathrm{S}$.
Onogi, ibid., 3, 116 (1970).

15. T. Masuda, K. Kitagawa, and S. Onogi, Polymer. J., 1, 418 (1970).

16. S. Onogi, T. Masuda, N. Toda, and K. Koga, ibid., 1, 542 (1970).

17. T. Altares, Jr., D. P. Wyman, and V. R. Allen, J. Polym. Sci., Part A, 2, 4533 (1964).

18. T. Ogami, K. Kawahara, and M. Ueda, Nippon Kagaku Zasshi (J. Chem. Soc., Pure Chem. Sect.), 79, 727 (1958). 